\title{
Access to treatment for multiple sclerosis must be based on science, not hope
}

Previously published at www.cmaj.ca

$\mathrm{T}$ he controversial venous angioplasty procedure proposed as a novel treatment for multiple sclerosis by Zamboni and colleagues ${ }^{1}$ has generated substantial public debate for an untested procedure first reported mere months ago. Patients and their advocates have held well-publicized demonstrations demanding access to the procedure. In Ottawa, some MPs are lobbying the federal government for millions of dollars in new funding for multiple sclerosis research and this new treatment. Desperation has even led some patients to file a lawsuit against the $\mathrm{BC}$ government claiming that denying access is discriminatory. ${ }^{2}$ But do we want hopeful media reports, special interest groups and political opportunism to decide which treatments we should study, provide and insure?

The idea that multiple sclerosis is caused by chronic cerebrospinal venous insufficiency and can be treated successfully by percutaneous angioplasty of venous strictures is both novel and unexpected. To date, the published evidence is limited to a case series of 65 patients. ${ }^{1}$ The results reported by Zamboni and colleagues - greater freedom from relapse (50\% v. $27 \%$ ) and fewer lesions seen by magnetic resonance imaging (12\% v. 50\%) seem promising but remain untested in controlled randomized trials. In addition, we are lacking a great deal of the relevant basic science, knowledge about the normal anatomy of the venous system, and links between venous anomalies and symptoms of multiple sclerosis.

Multiple sclerosis is difficult to study because most clinically relevant outcomes are subjective and because the natural history follows a waxing and waning course. These features make it challenging to ascribe benefit to treatment in the absence of a control group. No wonder that skepticism abounds in the medical and scientific communities about this treatment.

Many patients with multiple sclerosis understand these arguments; nevertheless, they insist that venous angioplasty be offered to them. They can hardly be blamed for this. Understandably, they fear ongoing loss of function and premature death. But good health policy decisions should not based on hope and desperation.

On the other hand, scientists and skeptics should avoid dismissing novel ideas prematurely. It is precisely the unexpected scientific discovery that often leads to major advances in care. The Nobel Prize-winning discovery that infection with Helicobacter pylori is a leading cause of peptic ulcer disease was met with widespread skepticism that delayed its translation to further research and practice. Unfortunately, for each major discovery, there are hundreds if not thousands of failures, where seemingly promising therapies prove useless and even harmful.

This controversy over access to novel treatment illustrates how quickly news of promising scientific discoveries can create unrealistic expectations. In contrast to novel medications, all other health interventions have few regulations to help manage expectations with proper evaluation. As a consequence, unproven therapies can be rapidly introduced into practice, overwhelming our ability to evaluate their safety and effectiveness. Regulating the complex process of developing and testing procedures won't work. Rather, we need to build a new and ongoing capacity to initiate clinical studies in response to promising therapeutic discoveries.

A major part of this approach involves limiting access to experimental procedures to well-designed clinical studies or research programs. Doing so will ensure access to innovative care for all patients while ensuring that the procedures are introduced safely into practice with appropriate evaluation. Hospital staff and clinicians have a duty to keep unproven therapies from premature use. Similarly, provincial governments should prevent public funds from being diverted to the use of drugs or procedures that lack evidence of safety and effectiveness.

Patients should insist on evidence. They should also insist on having their views represented when decisions about where to spend research dollars are made. With other diseases, such as breast cancer, patient advocates have successfully provided an important perspective in the decision-making process. It is only with patients that can research priorities can be set, implemented and tested so that we find better treatments.

The federal government should refrain from allotting funds for specific projects because (a) provinces may be incapable of dealing with the repercussions in clinical care; (b) we may not have organized clinical research networks able to design and execute a study; and (c) the project may not be feasible or the best one to take forward, once examined by experts and peer reviewers, given other promising alternatives.

Our tax dollars and charitable contributions should target research programs, networks and infrastructures that will leave long-lasting legacies, including a means to safely access innovations. Public funds should also address major questions that will improve care and health while promoting excellence. Failure to do so will leave our academic institutions and research community repeatedly at the mercy of advocacy campaigns and decisions based on political expediency and opportunism.

\section{Matthew B. Stanbrook MD PhD}

Deputy Editor, Scientific

Paul C. Hébert MD MHSc

Editor-in-Chief

CMAJ

With the editorial advisory team: Ken Flegel MDCM MSc and Noni MacDonald MD MSc

Competing interests: See www.cmaj.ca/misc/edboard.shtml

CMAJ 2010. DOI:10.1503/cmaj.100835

\section{REFERENCES}

1. Zamboni P, Galeotti R, Menegatti E, et al. A prospective open-label study of endovascular treatment of chronic cerebrospinal venous insufficiency. J Vasc Surg 2009;50:1348-58.

2. Feds urged to fund MS trial. CBC News. 2010 June 1. Available: www.cbc.ca /health/story/2010/06/01/ms-ccsvi-trial-funding.html (accessed 2010 June 14). 